Genitourin Med 1986; 62: 17-18

\title{
Chlamydia trachomatis infection in unmarried women seeking abortions
}

\author{
P CHAUDHURI,* E H SNG, $\dagger$ AND W S YUEN $\dagger$ \\ From the *Department of Obstetrics and Gynaecology, Toa Payoh Hospital, Singapore, and the $\dagger$ Department \\ of Microbiology, Singapore General Hospital, Singapore
}

SUMMARY Fifty consecutive unmarried women seeking termination of pregnancy in a state run general hospital in Singapore were screened for cervical Chlamydia trachomatis infection before abortion. Chlamydial infection was diagnosed by taking a cervical swab, culturing the organism in tissue culture media, and identifying the inclusion bodies by dark ground fluorescent microscopy.

Chlamydia trachomatis was recovered in as many as $14 \%$ of cases. None of the patients gave any history suggestive of promiscuity. Compared with gonorrhoea in the non-prostitute sexually active women of the population studied, the incidence of infection with Chlamydia trachomatis was found to be high. Patients with positive cultures often defaulted from follow up, thus posing a genuine risk of the spread of the disease by vertical and horizontal transmission.

\section{Introduction}

Infection with Chlamydia trachomatis is well known as a leading preventable cause of blindness in many developing countries. In recent years, however, it has been the subject of great interest and intensive research among venereologists, microbiologists, and gynaecologists. Chlamydia trachomatis is now regarded as the most common sexually transmitted pathogen in Western industrialised countries. ${ }^{1}$ In the United States 3-5 million women are estimated to suffer from chlamydial infection each year.

The bizarre pattern of the disease and the array of complications affecting men, women, and children have caused great concern in the Western hemisphere. Little information, however, is available about the extent of the disease in Asian countries. Our study, the first of its kind from South East Asia, aims to make a preliminary assessment of the magnitude of the problem associated with chlamydial infection to prompt awareness and stimulate further research in this field.

\section{Patients and methods}

We studied 50 consecutive unmarried women seeking termination of pregnancy in a state run general

Address for reprints: Dr P Chaudhuri, 84 Telok Blangah Heights, 07-329, Singapore 0410, Republic of Singapore

Accepted for publication 12 April 1985 hospital in Singapore between September 1983 and February 1984.

After informed consent had been obtained and just before abortion, material from the cervix was taken using a "Calgiswab" (Inolex, Illinois, USA). The swab was then expressed into $1 \mathrm{ml}$ of $0.2 \mathrm{~mol} / 1$ sucrose-phosphate buffer containing $5 \%$ fetal calf serum, $125 \mathrm{mg} / \mathrm{l}$ vancomycin, $50 \mathrm{mg} / \mathrm{l}$ streptomycin, and $25 \mathrm{IU} / \mathrm{ml}$ nystatin. The transport medium was kept at $4^{\circ} \mathrm{C}$ until it reached the laboratory, where it was stored at $-70^{\circ} \mathrm{C}$ until it was processed. Cycloheximide treated McCoy cells were used for cultivating the organism. After incubation for $\mathbf{4 8}$ and 72 hours, the coverslips were stained with Giemsa stain and chlamydiae were diagnosed by the detection of fluorescent inclusions under dark ground microscope.

Results

Chlamydia trachomatis was found in the cervices of seven $(14 \%)$ patients, four of whom defaulted from follow up despite repeated calls.

The mean age of the patients studied was 20 (range 15 to 28) years. About one fifth of the patients were unemployed, including one schoolgirl. Of those employed, only one was earning more than US\$300 a month. Forty eight $(96 \%)$ patients were nulliparous. None of the women had had multiple sexual partners. No consistent pattern of coital habit, use of contraception, or attitude towards premarital sexual experience was seen. The prospect of marriage was uncertain in all but one case. 


\section{Discussion}

Recognition of sexually transmitted diseases (STD), their treatment, and the prevention of their spread are important objectives of preventive medicine. To obtain optimum results, attention must be focussed both on prostitutes and non-prostitutes. Whereas the former group continues to receive attention, which leads to a decline in the global incidence of STD, scant attention has been paid to the latter group. This is mainly because the incidence of STD is very low in the non-prostitute population.

Chaudhuri et al found a very low incidence of gonorrhoea in non-prostitute sexually active women in Singapore. ${ }^{2}{ }^{3}$ In contrast, the study reported here indicates that the incidence of chlamydial infection, particularly in sexually active unmarried women, appears to be significantly high $(p>0.001)$. This is a matter of great concern. The reluctance of patients harbouring cervical chlamydiae to seek treatment is serious and favours spread of the disease. Doctors should be aware of this problem when dealing with unmarried pregnant women.

Users of oral contraceptives and partners of men with non-gonococcal urethritis (NGU) are also known to be at high risk of harbouring cervical chlamydial infection. In Singapore, the incidence of NGU in men is as much as $20 \%,{ }^{4}$ and there is evidence that this disorder is on the increase.

Children born to mothers harbouring cervical chlamydiae run a 30 to $50 \%$ risk of inclusion conjunctivitis and a 10 to $20 \%$ risk of neonatal pneumonia. ${ }^{15-7}$ The cost benefit analysis developed by Schachter and Grossman indicated that the break even point was a $6 \%$ rate of cervical infection. At above this point, the cost of treatment of complications of chlamydial infection in infants would exceed the cost of screening and treating all pregnant women to prevent perinatal exposure. ${ }^{8}$ When the cost of treatment of other complications of chlamydial infection in men and women, loss of productivity during time in hospital and convalescence, and the intangible cost of human suffering are taken into account, it may be justifiable • to screen all women for chlamydial infection at the first opportunity.

The study published here points to the tip of a possible iceberg. Further research in this topic in the East is urgently required to reduce morbidity associated with chlamydial infection and to prevent the spread of the disease by vertical and horizontal transmission. The attitude towards contraception and premarital sex has been found to be one of indifference. The need for a proper sex education and counselling in the population studied is, therefore, apparent.

We thank Dr B Y Lau, Medical Director, Toa Payoh Hospital, and Dr Moses Yu, Medical Director, Dept of Pathology, Ministry of Health, Republic of Singapore, for their inspiration and support in the conduct of this research project. Our thanks are also due to the medical and nursing staff of Ward 7 of Toa Payoh Hospital for their unfailing help and co-operation.

\section{References}

1. Schachter J. Chlamydial infections. $N$ Engl $J$ Med 1978;298:428-35, 490-5, 540-9.

2. Chaudhuri P, Hoon ML, Vengadasalam D, Sng EH. Prevalence of gonorrhoea in women seeking abortions: a prospective study. Singapore Journal of Obstetrics and Gynaecology 1983;14:133-5.

3. Chaudhuri P, Tay BL, Sng EH. Prevalence of gonorrhoea in unmarried women seeking termination of pregnancy: initial impression in Singapore. Singapore Journal of Obstetrics and Gynaecology 1984;15:112-4.

4. Lim KB. Nonspecific genital infection (NSGI) of the female. The Singapore Family Physician 1983;9:130-3.

5. Schachter J, Holt J, Goodner E, Grossman M, Sweet R, Mills J. Prospective study of chlamydial infection in neonates. Lancet 1979;ii:377-80.

6 Hammerschlag MR, Anderka M, Semine DZ, McComb D, McCormack WM. Prospective study of maternal and infantile infection of mothers and their infants. I Pediatr 1979:95:288.

7. Frommel GT, Rothenberg R, Wang SP, et al. Chlamydial infection of mothers and their infants. $J$ Pediatr 1979;95:28.

8. 32 Schachter J, Grossman M. Chlamydial infections. Annu Kev Med 1981;32:45-61. 